\title{
Influence of chemical composition and doping on optical properties of thallium selenide layers prepared by adsorption/diffusion method
}

\author{
Linas Samardokas, \\ Remigijus Ivanauskas, \\ Skirma Žalenkienè, \\ Algimantas Ivanauskas \\ Department of Physical \\ and Inorganic Chemistry, \\ Kaunas University of Technology, \\ 19 Radvilenu Street, \\ 50254 Kaunas, Lithuania
}

In this work, we investigated the formation of Tl-Se layers followed by doping with metal cations. A two-stage adsorption/diffusion process used to form Tl-Se layers involves (a) selenization in potassium selenotrithionate solution followed by (b) treatment with $\mathrm{Tl}^{+}$precursor solutions. These layers have been successfully doped with $\mathrm{Cu}^{+} / \mathrm{Cu}^{2+}, \mathrm{Ga}^{3+}$ and $\mathrm{Ag}^{+}$cations using a cation exchange reaction. The resulting chemical compositions of Tl-Se and Tl-M-Se $(\mathrm{M}=\mathrm{Cu}, \mathrm{Ga}, \mathrm{Ag})$ layers were investigated using the EDS and AAS methods. The bulk elemental composition and the Tl/Se molar ratio of the Tl-Se layers varied with the concentration of the $\mathrm{Tl}^{+}$precursor solution, the exposure time in the $\mathrm{Tl}^{+}$precursor solution, and the form of the $\mathrm{Tl}^{+}$in the solution, whereas the EDS analysis showed that the surface was slightly enriched in thallium. The optical properties of the formed layers were studied. These layers were identified using room temperature reflection spectrum, the values of absorption edge, bandgap $\left(E_{g}\right)$, band tail width (Urbach energy, $\left.E_{U}\right)$ of the localised states, Steepness parameter $(\sigma)$ and electron-phonon interaction $\left(E_{e-p}\right)$.

Keywords: polyamide, thallium selenide layers, doping, optical properties

\section{INTRODUCTION}

Organic/inorganic mixed composites are rapidly developing group of materials with a remarkable range of highly tunable physical, structural and chemical properties. Polymers modified by thin films of binary d-metal chalcogenides belong to the composite materials as well. These composites promise to be valuable in solar energy conversion [1, 2], thermoelectrics [3, 4], photocatalysis [5], photodetectors [6], light-emitting diodes [7] and so on. Group III metal (Ga, In and Tl) composite materials binary or ternary compounds combined with group VI nonmetals (S, Se and Te)

* Corresponding author. Email: remigijus.ivanauskas@ktu.lt have very important and unique physical properties to technology and modern science. For example, GaSe is used to convert far-infrared light [8], InSe in optoelectronic devices [9] since, properly grown or doped $\mathrm{In}_{2} \mathrm{Se}_{3}$ shows either $\mathrm{n}$ - or $\mathrm{p}$-type conduction and is used in various optoelectronic devices [10] $\mathrm{Tl}_{2} \mathrm{~S}$ and $\mathrm{TlS}$ are photoconductors [11. 12. while $\mathrm{Tl}_{5} \mathrm{Te}_{3}$ is a superconductor at low temperatures [13]. In modern microelectronics, thallium selenides can be used for production of photoconductors and photocells [14, 15]. Meanwhile, the conversion of binary selenides to ternary or the incorporation of metal ions into them greatly improves their qualitative characteristics. For example, solar cells based on $\mathrm{CuGaSe}_{2}, \mathrm{CuInSe}_{2}$ and $\mathrm{CuInS}_{2}$ widely used in solar energy harvesting 
have an efficiency of $18.8 \%$ [16]. Therefore, many studies have focused on methods for the preparation of these ternary selenide thin films, such as spray pirolysis [17], direct current-magnetron sputtering [18], thermal co-evaporation [19], low temperature pulsed electron deposition [20], electrodeposition [12], solvothermal [21] and others. However, most of these methods typically consist of many stages, require sophisticated equipment and special conditions such as high temperature, vacuum, and conductive substrates, making them unsuitable and expensive for manufacturing most polymers. Thus, there is a significant interest in the formation of ternary selenide films by wet chemical methods such as the successive ionic layer adsorption and reaction (SILAR) [22, 23, and the chemical bath deposition (CBD) [24]. It would be even more simple and appropriate to form by wet chemical methods composite doped binary layers on the surface of polymers instead of ternary Group III metal chalcogenide layers [25, 26. In particular, doped layers of metal chalcogenides are promising for optical applications, because the doping procedure makes it possible to expand the optoelectronic properties of these layers on a large scale [27, 28]. Moreover, doping provides the ability to tune a synthesised metal chalcogenide layer and solution properties while being viable for large-scale application.

In this study, the adsorption diffusion two-stage method, very similar to the SILAR method, was used to form a binary thallium selenide layer on a polyamide (PA) sheet. Polyamide is a semi-hydrophilic polymer capable of absorbing electrolytes from solutions [29]. This fact previously allowed the incorporation of selenotrithionionate anions $\left(\mathrm{SeS}_{2} \mathrm{O}^{2-}\right)$ from aqueous solutions into the PA substrate [30]. After treating these anion-containing polyamide samples with aqueous solutions of metal cations different binary metal selenide layers on the polymer surface were obtained [31-37].

In the present work, thallium selenide thin layers with varying ratios of thallium to selenium were deposited onto polyamide sheet substrates using the adsorption/diffusion method. To further improve the photoelectric properties of the Tl-Se layers, some metal cations, such as silver, gallium and copper, were doped into the Tl-Se layers. Then, the optical properties of the formed Tl-Se and Tl-M-Se layers were studied.

\section{EXPERIMENTAL}

\section{Materials and methods}

The layers of thallium selenide were formed on polyamide 6 sheets (further PA sheets) (Tecamid 6, $500 \mu \mathrm{m}$ thickness, Germany) substrate. The porosity pf PA sheets was measured by a Brunauer Emmett Teller (BET) method using a Quantasorb (USA). The estimated polymer pore size is less than $1.5 \mathrm{~nm}$. This means that PA is basically non porous [38]. Prior to selenisation, the polymer samples were placed in boiling distilled water for $2 \mathrm{~h}$ to remove the remainder of the monomer. Then they were dried and kept in a desiccator over $\mathrm{CaCl}_{2}$ for $24 \mathrm{~h}$. The thallium selenide layer on PA sheets formation procedure as well as the doping of these layers with different metal cations are shown in Fig. 1. The samples of polymer sheets thus prepared were treated for $1.5 \mathrm{~h}$ in a thermostatic vessel using continually stirred $0.05 \mathrm{~mol} \cdot \mathrm{dm}^{-3}$ solutions of $\mathrm{K}_{2} \mathrm{SeS}_{2} \mathrm{O}_{6}$ in $0.1 \mathrm{~mol} / \mathrm{l} \mathrm{HCl}$ at $60^{\circ} \mathrm{C}$.

The salt of potassium selenotrithionate, $\mathrm{K}_{2} \mathrm{SeS}_{2} \mathrm{O}_{6}$, was synthesised according to the procedure reported previously [39]. The selenised samples of the PA sheet were treated with basic solutions of thallium nitrate or thallium sulfate salts. These experimental conditions are summarised in Table 1 . $\mathrm{pH}$ of the thallium salt solution was adjusted using granules of potassium hydroxide or $25 \%$ ammonia solution. Next, to form mixed Tl-M-Se $(\mathrm{M}=\mathrm{Cu}$, $\mathrm{Ga}, \mathrm{Ag}$ ) type layers, the PA sheets with Tl-Se layers were doped with solutions containing $\mathrm{Cu}^{2+} / \mathrm{Cu}^{+}$, $\mathrm{Ga}^{3+}$ and $\mathrm{Ag}^{+}$cations. These doping conditions are summarised in Table 2. Hydroquinone as a reducing agent for preparing a mixture of univalent and divalent copper salts was used. This mixture consisted of $0.34 \mathrm{M} \mathrm{Cu}(\mathrm{II})$ and $0.06 \mathrm{M} \mathrm{Cu}(\mathrm{I})$ salt. Trisodium citrate $\left(\mathrm{Na}_{3} \mathrm{C}_{6} \mathrm{H}_{5} \mathrm{O}_{7}\right)$ as a complexing agent for the formation complex $\left[\mathrm{Ga}_{3}\left(\mathrm{C}_{6} \mathrm{H}_{5} \mathrm{O}_{7}\right)_{2}\right]$ was used. It was applied to maintain soluble species of $\mathrm{Ga}^{3+}$ in an aqueous medium as it allows control of the $\mathrm{Ga}^{3+}$ concentration.

All reagents used in the experiments were chemically and analytically pure commercial reagents: selenium (Se) pellets (100 mesh powder, $99.99 \%$ trace metals basis from Aldrich), selenous acid $\left(\mathrm{H}_{2} \mathrm{SeO}_{3}\right)$ (99.999\% trace metals basis from Sigma-Aldrich), hydrochloric acid $(\mathrm{HCl}) \quad 0.1 \mathrm{M}$ from Fluka, potassium 


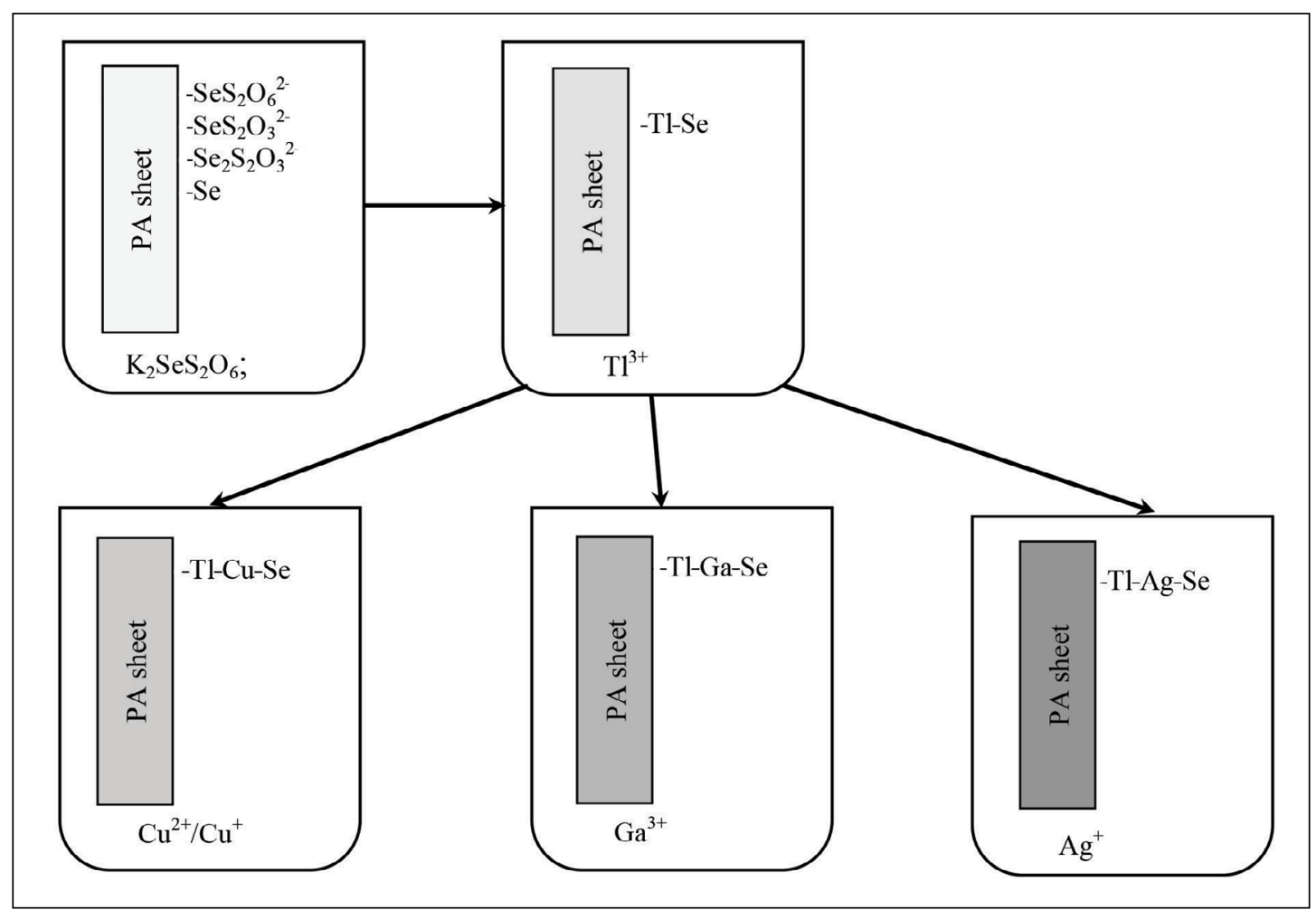

Fig. 1. Schematics depicting the synthesis and doping procedures of TI-Se films on PA sheets substrate. Coloured online

Table 1. Conditions for treatment of selenized PA sheets with thallium salt solutions

\begin{tabular}{|c|c|c|c|c|c|c|}
\hline $\begin{array}{c}\text { Duration of } \\
\text { selenisation, } h\end{array}$ & $\begin{array}{l}\text { Precursor } \\
\text { of TI(I) }\end{array}$ & $\begin{array}{c}\text { Concentration of } \mathrm{TI}(\mathrm{I}) \text { soliution, } \\
\mathrm{mol} / \mathrm{I}\end{array}$ & $\begin{array}{l}\text { Temperature, } \\
{ }^{\circ} \mathrm{C}\end{array}$ & pH adjusting agent & pH & $\begin{array}{l}\text { Duration, } \\
\text { min }\end{array}$ \\
\hline 1.5 & $\mathrm{TINO}_{3}$ & $0.025-0.8$ & 60 & $\mathrm{KOH}$ & 11.5 & 75 \\
\hline 1.5 & $\mathrm{Tl}_{2} \mathrm{SO}_{4}$ & 0.1 & 60 & $25 \% \mathrm{NH}_{3} \cdot \mathrm{H}_{2} \mathrm{O}$ & 10.9 & 20,75 \\
\hline
\end{tabular}

Table 2. Doping conditions of TI-Se layers on PA sheets

\begin{tabular}{|c|c|c|c|c|c|}
\hline Type of film & Precursor & Concentration, $\mathrm{mol} / \mathrm{l}$ & Additives & Temperature, ${ }^{\circ} \mathrm{C}$ & Duration, $\min$ \\
\hline Tl-Cu-Se & $\mathrm{CuSO}_{4}$ & 0.4 & $1 \%$ hydroquinone & 80 & 15 \\
\hline Tl-Ga-Se & $\mathrm{Ga}_{2}\left(\mathrm{SO}_{4}\right)_{3}$ & 0.025 & $\begin{array}{c}\mathrm{NH}_{3} \cdot \mathrm{H}_{2} \mathrm{O} \\
(\mathrm{pH} 10.50) . \\
0.025 \mathrm{M} \text { trisodium } \\
\text { citrate }\end{array}$ & 60 & 60 \\
\hline $\mathrm{Tl}-\mathrm{Ag}-\mathrm{Se}$ & $\mathrm{AgNO}_{3}$ & 0.1 & - & 80 & 15 \\
\hline
\end{tabular}

hydroxide $(\mathrm{KOH})$ (reagent grade, $90 \%$, flakes from Sigma-Aldrich), potassium disulphite $\left(\mathrm{K}_{2} \mathrm{~S}_{2} \mathrm{O}_{5}\right)$ ( $\geq 98.0 \%$ from Sigma-Aldrich), thallium sulphate $\left(\mathrm{Tl}_{2} \mathrm{SO}_{4}\right)(\geq 99.9 \%$ trace metals basis from Aldrich), thallium nitrate $\left(\mathrm{TlNO}_{3}\right) \quad(\geq 99.9 \%$ trace metals basis from Aldrich), 25\% ammonia solution $\left(\mathrm{NH}_{4} \mathrm{OH}\right)$, gallium sulphate $\left(\mathrm{Ga}_{2}\left(\mathrm{SO}_{4}\right)_{3}\right)$, crystalline copper sulphate pentahydrate $\left(\mathrm{CuSO}_{4} \cdot 5 \mathrm{H}_{2} \mathrm{O}\right)$ (crystals and lumps, $99.999 \%$ trace metals basis, from Sigma-Aldrich), silver nitrate $\left(\mathrm{AgNO}_{3}\right)$, hydroquinone $\left(\mathrm{C}_{6} \mathrm{H}_{4}(\mathrm{OH})_{2}\right)$ (flakes, $\geq 99 \%$ Rea-
gentPlus ${ }^{\circledast}$ from Sigma-Aldrich), trisodium citrate $\left(\mathrm{Na}_{3} \mathrm{C}_{6} \mathrm{H}_{5} \mathrm{O}_{7}\right)$.

The total amounts of thallium, selenium, copper, gallium and silver in metal selenide layers formed on the surface of PA sheets surface were determined from the atomic absorption spectrophotometry (AAS) method using a Shimadzu AA-7000 (Shimadzu Corporation, Japan). Before the analysis, the modified PA sheets were treated in a hot solution of concentrated $\mathrm{HNO}_{3}$ and deionised water (1:1) to digest the PA and to oxidise any 
selenium compounds into selenites. The measured wavelengths were used: for $\mathrm{Tl}$ at $276.8 \mathrm{~nm}$, for Se at $196.03 \mathrm{~nm}$, for copper $324.8 \mathrm{~nm}$, for gallium $\lambda=287.4 \mathrm{~nm}$ and for $\mathrm{Ag}$ at $328.07 \mathrm{~nm}$. The sensitivity of analysis is about $0.5 \mu \mathrm{g} / \mathrm{ml}$ for selenium and thallium, $0.1 \mu \mathrm{g} / \mathrm{ml}$ for copper, $10 \mu \mathrm{g} / \mathrm{ml}$ for gallium and $0.2 \mu \mathrm{g} / \mathrm{ml}$ for silver for $1 \%$ absorption.

The surface elemental analysis of the formed layers was determined from the energy-dispersive X-ray spectroscopy (EDS) method by using a Bruker XFlash 4030 detector (Bruker AXS Microanalysis $\mathrm{GmbH}$, Germany). The standardless ZAF method was used to quantify elements detected with EDS.

Optical properties of Tl-Se layers and mixed Tl-M-Se layers were measured using a PerkinElmer Lambda 35 UV/VIS spectrometer (Thermo Fischer Scientific, USA), the Labsphere RSA-PE-20 Diffuse Reflectance Sphere in the range of $400-1100 \mathrm{~nm}$.

\section{RESULTS AND DISCUSSION}

Thin film is formed on the polymer surface when the substrate is exposed to an aqueous $\mathrm{SeS}_{2} \mathrm{O}_{6}{ }^{2-}$ solution. This results in strong adhesion between the formed thin film and polymer substrate, thanks to the partial diffusion of $\mathrm{SeS}_{2} \mathrm{O}_{6}^{2-}$ ions and its decomposition products as secondary ions, such as $\mathrm{SeSO}_{3}{ }^{2-}$ and $\mathrm{Se}_{2} \mathrm{~S}_{2} \mathrm{O}_{6}{ }^{2-}[30]$, into the polymer itself.

Thallium selenide can then be formed during the reactions of these ions with $\mathrm{Tl}^{+}$cations [31] as described by the following reactions $(1-3)$ :

$$
\begin{aligned}
& 2 \mathrm{Tl}^{+}+\mathrm{SeS}_{2} \mathrm{O}_{6}{ }^{2-}+4 \mathrm{OH}^{-} \rightarrow \\
& \mathrm{Tl}_{2} \mathrm{Se}+2 \mathrm{SO}_{4}{ }^{2-}+2 \mathrm{H}_{2} \mathrm{O}, \\
& 2 \mathrm{Tl}^{+}+\mathrm{Se}_{2} \mathrm{~S}_{2} \mathrm{O}_{6}{ }^{2-}+4 \mathrm{OH}^{-} \rightarrow \\
& \mathrm{Tl}_{2} \mathrm{Se}+\mathrm{Se}+2 \mathrm{SO}_{4}^{2-}+2 \mathrm{H}_{2} \mathrm{O}, \\
& 2 \mathrm{Tl}^{+}+\mathrm{SeSO}_{3}{ }^{2-}+2 \mathrm{OH}^{-} \rightarrow \\
& \mathrm{Tl}_{2} \mathrm{Se}+\mathrm{SO}_{4}{ }^{2-}+\mathrm{H}_{2} \mathrm{O} .
\end{aligned}
$$

Precursor concentration, the form of cations in the precursor solution, duration of reaction, and temperature are important parameters that have a decisive influence on the morphology, thickness and composition of metal chalcogenide films [40]. Therefore, firstly, the influence of the concentration of thallium precursor solution on the thallium concentration and $\mathrm{Tl} / \mathrm{Se}$ ratio in the $\mathrm{Tl}-\mathrm{Se}$ layers formed on the surface of PA sheets substrate was investigated. In order to obtain higher concentration solutions of the $\mathrm{Tl}^{+}$precursor, $\mathrm{TlNO}_{3} \leftrightarrow 3 \mathrm{H}_{2} \mathrm{O}$ salt was also used, the solubility of which is significantly higher than that of $\mathrm{Tl}_{2} \mathrm{SO}_{4}[41]$.

The presence of stratified Tl-Se layers was confirmed by elemental EDS analysis on the electron-rich film and deeper layers of the polyamide sheets. The degree of interaction between the electron beam and the sample is identified as in EDS analysis depth sampling. It correlates with the kinetic energy of electrons and the atomic number of atoms analysed. The analysis can obtain results within a few $\mu \mathrm{m}$ depths. The representative EDS spectra of Tl-Se layers formed using various thallium nitrate concentrations are shown in Fig. 2. Elemental peaks are observed in 0 to $3 \mathrm{keV}$ energy range. Based on this data, several comments can be made. First, the dominant peaks are associated with complex $\mathrm{C}$ and $\mathrm{O} \mathrm{X}$-ray lines, as well as with weaker signals of $\mathrm{Tl}$ and Se. Second, the nitrogen peaks associated with the polyamide structure are not observed at $0.392 \mathrm{keV}\left(\mathrm{K}_{\alpha}\right)$ in the spectra, possibly because they overlap with the more intense peaks of carbon at $0.277 \mathrm{keV}\left(\mathrm{K}_{\alpha}\right)$ and oxygen at $0.525 \mathrm{keV}\left(\mathrm{K}_{\alpha}\right)$. The $\mathrm{Tl}$ and Se peaks originating from the Tl-Se layer confirm the formation of well-defined thin layers in the PA sheet substrate.

Samples formed using $0.025 \mathrm{~mol} / \mathrm{l}$ and $0.1 \mathrm{~mol} / \mathrm{l}$ $\mathrm{Tl}^{+}$ion precursor concentrations have almost identical EDS spectra. When the $\mathrm{TlNO}_{3}$ solution with the highest concentration of $0.8 \mathrm{~mol} / \mathrm{l}$ was used to form the sample, EDS spectra resulted in more intense thallium and selenium peaks, also lower carbon peak due to higher amounts of formed thallium selenide layers.

The EDS spectra of Tl-Se layers formed using various durations from thallium sulfate solutions are shown in Fig. 3. The results show a similar effect on the concentration of $\mathrm{Tl}^{+}$precursor solution. More intense thallium, selenium, and lower carbon peaks are observed due to higher amounts of deposited thallium selenide layers. Having formed a thin layer of Tl-Se, at the next 


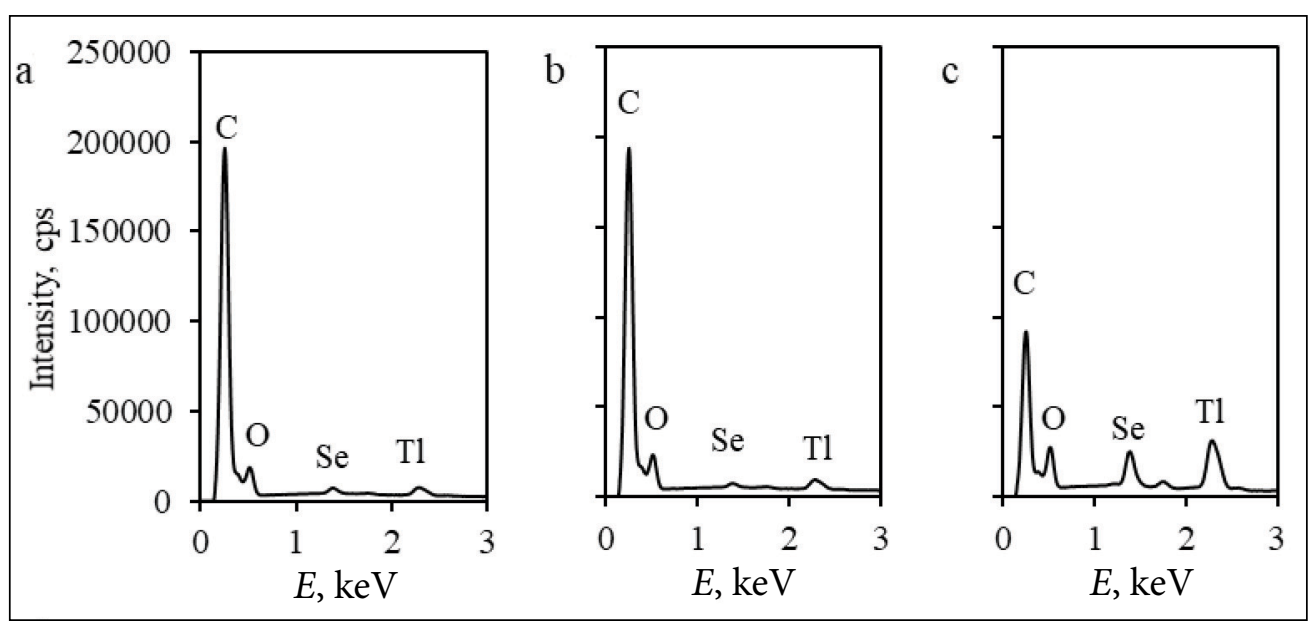

Fig. 2. Representative EDS patterns of the surfaces of TI-Se layers formed by use of different concentrations of thallium nitrate solution. Concentration, $\mathrm{mol} / \mathrm{l}$ : (a) 0.025 , (b) 0.1 , (c) 0.8 . The data of the corresponding elemental analysis assessed by EDS are shown in Table 3

stage, we estimated the amount of $\mathrm{Tl}$ and $\mathrm{Se}$ in it using the analysis of AAS and EDS. The results of analysis are tabulated in Table 3 .

The results of atomic absorption spectroscopy analysis show that with increasing $\mathrm{Tl}^{+}$concentra-

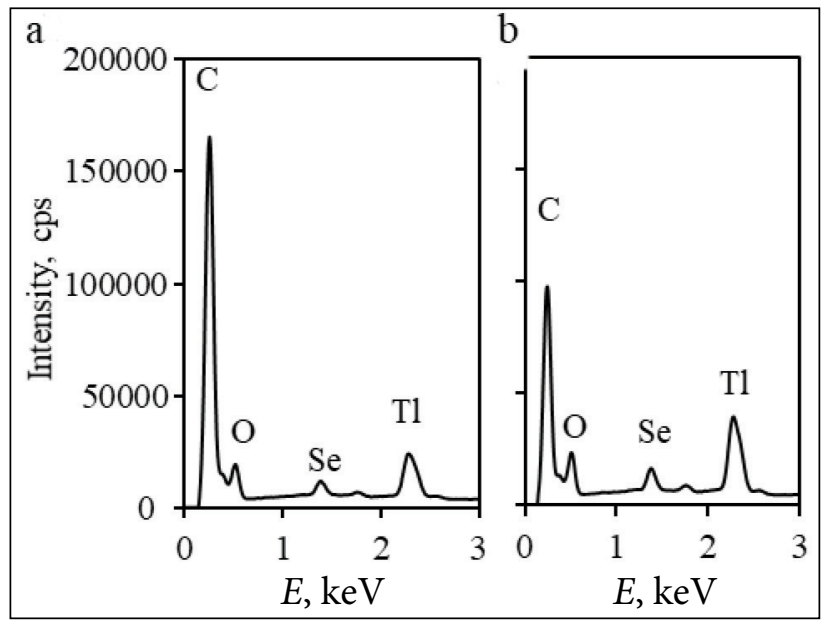

Fig. 3. Representative EDS patterns of the surfaces of TI-Se layers formed by using different durations of treatment with thallium sulfate solution. Duration, min: (a) 20, (b) 75. The data of the corresponding elemental analysis assessed by EDS are shown in Table 3 tion in the precursor solutions, although the concentration of selenium in the polymer is almost unchanged, the thallium concentration in PA sheet samples increases from 0.129 to $0.493 \mu \mathrm{mol} / \mathrm{cm}^{2}$, and the molar Tl/Se ratio increases from 0.105 to 0.401 . The increase in the duration of treatment selenised PA sheets with the $\mathrm{Tl}^{+}$precursor solution has a positive effect on an increase in the concentration of thallium and the molar ratio of $\mathrm{Tl} / \mathrm{Se}$ in the samples of PA sheets with Tl-Se layers.

Meanwhile, the EDS analysis shows that the Tl/Se molar ratio in the layers is significantly higher than that determined by the AAS method. As the data presented in Table 3 shows, the Tl/Se molar ratio in the Tl-Se layers on the PA sheet increases from 1.057 to 1.663 with the increase in the concentration of the thallium nitrate solution. This is because while AAS represents the bulk elemental composition of Tl-Se composites, energy dispersive X-ray spectroscopy provides insights into the compositional information of the outermost surface of obtained layers.

The dependence of the elemental composition of the surface layer of samples on the duration of

Table 3. Surface and bulk elemental composition of thallium selenide layers

\begin{tabular}{|c|c|c|c|c|c|c|}
\hline Concentration of $\mathrm{Tl}^{+}$soliution, $\mathrm{mol} / \mathrm{l}$ & Duration, min & Tl, at \% & Se, at $\%$ & $\mathrm{TI} / \mathrm{Se}$ (EDS) & $\mathrm{Tl}, \mu \mathrm{mol} / \mathrm{cm}^{2}$ & $\mathrm{Tl} / \mathrm{Se}$ (AAS) \\
\hline 0.025 & \multirow{3}{*}{75} & 51.38 & 48.62 & 1.057 & 0.129 & 0.105 \\
\hline 0.1 & & 52.65 & 47.35 & 1.112 & 0.190 & 0.154 \\
\hline 0.8 & & 62.45 & 37.55 & 1.663 & 0.493 & 0.401 \\
\hline \multirow{2}{*}{0.1} & 20 & 70.22 & 29.78 & 2.36 & 0.855 & 0.695 \\
\hline & 75 & 68.11 & 31.89 & 2.14 & 1.541 & 1.253 \\
\hline
\end{tabular}

Amount of selenium determined by the AAS method is $1.23 \mu \mathrm{mol} / \mathrm{cm}^{2}$. 
treatment with the precursor solution of $\mathrm{Tl}^{+}$ion was also investigated by the EDS method. The selenised samples were treated for 20 and $75 \mathrm{~min}$ in a $60^{\circ} \mathrm{C}$ solution of thallium sulfate at $\mathrm{pH} 10.9$ (the solution medium was adjusted with $25 \%$ ammonia solution). Under these synthesis conditions, a higher concentration of $\mathrm{Tl}^{+}$ions and a $\mathrm{Tl} / \mathrm{Se}$ molar ratio are obtained both on the surface of the layer and in the entire volume of the coating (Table 3). Thus, the thallium ammonia complex is more suitable for forming thallium selenide layers. It is necessary to note that the thallium ammonia complex allows one to control the $\mathrm{Tl}^{+}$concentration and to have soluble stable $\mathrm{Tl}^{+}$species in an aqueous medium. When the ammonia solution is added, the $\mathrm{Tl}^{+}$ion in a solution of the $\mathrm{Tl}_{2} \mathrm{SO}_{4}$ salt according to Eq. (4) forms the complex:

$$
\begin{aligned}
& \mathrm{Tl}^{+}+2 \mathrm{NH}_{3} \leftrightarrow \mathrm{H}_{2} \mathrm{O} \rightarrow \\
& {\left[\mathrm{Tl}\left(\mathrm{NH}_{3}\right)_{2}\right]^{+}+2 \mathrm{H}_{2} \mathrm{O} .}
\end{aligned}
$$

These complex ions are slowly adsorbed/diffused into the selenised PA sheet and simultaneously react with ions containing divalent selenium according to Eqs. (5-7):

$$
\begin{aligned}
& 2\left[\mathrm{Tl}\left(\mathrm{NH}_{3}\right)_{2}\right]^{+}+\mathrm{SeS}_{2} \mathrm{O}_{6}{ }^{2-}+2 \mathrm{H}_{2} \mathrm{O} \rightarrow \\
& \mathrm{Tl}_{2} \mathrm{Se}+2\left(\mathrm{NH}_{4}\right)_{2} \mathrm{SO}_{4}, \\
& 2\left[\mathrm{Tl}\left(\mathrm{NH}_{3}\right)_{2}\right]^{+}+\mathrm{Se}_{2} \mathrm{~S}_{2} \mathrm{O}_{6}{ }^{2-}+2 \mathrm{H}_{2} \mathrm{O} \rightarrow \\
& \mathrm{Tl}_{2} \mathrm{Se}+\mathrm{Se}+2\left(\mathrm{NH}_{4}\right)_{2} \mathrm{SO}_{4}, \\
& 2\left[\mathrm{Tl}\left(\mathrm{NH}_{3}\right)_{2}\right]^{+}+\mathrm{SeSO}_{3}{ }^{2-}+\mathrm{H}_{2} \mathrm{O} \rightarrow \\
& \mathrm{Tl}_{2} \mathrm{Se}+\left(\mathrm{NH}_{4}\right)_{2} \mathrm{SO}_{4}+2 \mathrm{NH}_{3} .
\end{aligned}
$$

The formed $\mathrm{Tl}_{2} \mathrm{Se}$ and elemental selenium remain adsorbed on the polymer, while other compounds dissolve again in the solution.

The changing synthesis duration, in this case, has an unexpected result. The Tl/Se molar ratio determined by the AAS analysis increases from 0.695 to 1.253 with increasing treatment duration in the $\mathrm{Tl}^{+}$precursor solution from 20 to $75 \mathrm{~min}$, while this molar ratio determined by the EDS analysis decreases from 2.36 to 2.14 . This can be explained by the fact that an increase in duration has a positive effect on polymer swelling. It is known that water is necessary for the diffusion of ions into the polymer matrix [42]. Furthermore, the migration rate of ions in the polymer matrix is directed by the amount of water present. Water plasticises the polymer matrix and hydrates ions. With an increase in the treatment duration of the selenised PA sheet with the $\mathrm{Tl}^{+}$precursor solution, this process is enhanced. Subsequently, a larger number of water molecules, and with them, a larger number of $\mathrm{Tl}^{+}$ions, better penetrate into the deeper layers of the swollen polymer. Thus at the same time, a larger number of $\mathrm{Tl}^{+}$reacts with divalent selenium-containing compounds and forms layers into the PA substrate with a higher concentration of Tl-Se. However, not only $\mathrm{Tl}^{+}$ions diffuse into the deeper layer of the swollen polymer, but also at the same time, partial desorption of selenium-containing anions, already diffused into the polymer surface at the first stage, occurs. Therefore, the concentration of these ions in the polymer surface layers increases. It is known that the adsorbed/diffused into the PA sheet ions of selenopolythionates decompose to elemental selenium [30]. As a result, more elemental selenium is formed, which does not react with the precursor ions. When selenized, PA sheets are treated in a $\mathrm{Tl}_{2} \mathrm{SO}_{4}$ solution for $75 \mathrm{~min}$, the less thallium-rich layer is formed on the polymer surface for the reasons above.

To obtain $\mathrm{Ga}^{3+}, \mathrm{Cu}^{2+} / \mathrm{Cu}^{+}$or $\mathrm{Ag}^{+}$cations doped Tl-Se, the PA sheets with Tl-Se layers were formed with a $\mathrm{Tl}_{2} \mathrm{SO}_{4}$ solution for $20 \mathrm{~min}$, they were treated with the precursor solution of these cations at the conditions depicted in Table 2. Due to cationcation exchange reactions it is possible to form doped Tl-M-Se type layers. For the aforementioned reaction to occur, the value of the solubility of the Tl-Se layer must be higher than the value of the solubility of the selenide formed during doping. Definitely, the solubility products of $\mathrm{Tl}_{2} \mathrm{Se}$ $\left(\mathrm{K}_{\mathrm{sp}}=2.4 \times 10^{-22}(\mathrm{~mol} / \mathrm{l})^{3}\right)$ are very large compared to those of CuSe $\left(\mathrm{K}_{\mathrm{sp}}=1.4 \times 10^{-36}(\mathrm{~mol} / \mathrm{l})^{2}\right)$, $\mathrm{Cu}_{2} \mathrm{Se}\left(\mathrm{K}_{\mathrm{sp}}=1.1 \times 10^{-51}(\mathrm{~mol} / \mathrm{l})^{2}\right)$ and $\mathrm{Ag}_{2} \mathrm{Se}$ $\left(\mathrm{K}_{\mathrm{sp}}=3.1 \times 10^{-65}(\mathrm{~mol} / \mathrm{l})^{3}\right)$. The value of the $\mathrm{Ga}_{2} \mathrm{Se}_{3}$ solubility could not be found in the literature, but because $\mathrm{Ga}$ is a group IIIA element like $\mathrm{Tl}$, it is assumed that the value of the $\mathrm{Ga}_{2} \mathrm{Se}_{3}$ solubility is close to the $\mathrm{Tl}_{2} \mathrm{Se}$ value.

The data of element EDS analysis of these layers tabulated in Table 4 confirmed the presence of mixed Tl-M-Se $(\mathrm{M}=\mathrm{Cu}, \mathrm{Ga}, \mathrm{Ag})$ type layers on $\mathrm{PA}$ 
Table 4. Surface elemental composition of mixed TI-M-Se (M = Ga, $\mathrm{Cu}, \mathrm{Ag})$ type selenide layers

\begin{tabular}{c|ccc|c}
\hline Type of layer & Tl, at.\% & M, at.\% & Se, at.\% & Tl:M:Se \\
\hline Tl-Cu-Se & 7.83 & 44.43 & 47.74 & $0.18: 0.93: 1$ \\
\hline Tl-Ga-Se & 36.56 & 19.35 & 44.09 & $0.83: 0.44: 1$ \\
\hline Tl-Ag-Se & 4.78 & 58.32 & 36.91 & $0.13: 1.58: 1$ \\
\hline
\end{tabular}

sheets. The representative EDS spectra of these layers are shown in Fig. 4 . It can be seen that in the EDS spectra, in addition to the X-ray emission lines of carbon and oxygen belonging to the PA sheet matrix, there are distinct and well-matched peaks of copper $\mathrm{L}_{\alpha} 0.930 \mathrm{keV}$, and silver $\mathrm{L}_{\alpha 1} 2.984 \mathrm{keV}$ and $\mathrm{L}_{\beta 1} 3.151 \mathrm{keV}$ (for Tl-Ag-Se). However, in the TlGa-Se spectrum, the emission lines of all the main elements making up the layer are of low intensity and inexplicit. The highest concentration of the doped metal was achieved in the Tl-Ag-Se layers, the lowest in the Tl-Ga-Se layers, possibly due to the completely different solubility of the formed $\mathrm{Ag}_{2} \mathrm{Se}$ and $\mathrm{Ga}_{2} \mathrm{Se}_{3}$ during the doping procedure.

Optical properties of the formed Tl-Se and Tl$\mathrm{M}$-Se layers were studied by measuring reflection spectra in the $400-1100 \mathrm{~nm}$ range to obtain the values of absorption edge, band gap $\left(E_{g}\right)$, band tail width (Urbach energy, $E_{U}$ ) of the localised states, steepness parameter $(\sigma)$ and electron-phonon interaction $\left(E_{e-p}\right)$. First, the dependence of the optical parameters of the Tl-Se layers on the concentration of the thallium salt solution and the duration of the treatment process was investigated. As seen in Fig. $5 \mathrm{a}$, increasing the concentration of the $\mathrm{Tl}^{+}$ precursor solution from 0.025 to $0.8 \mathrm{~mol} / \mathrm{l}$ reduces the reflection of electromagnetic radiation in the entire wavelength range under consideration,

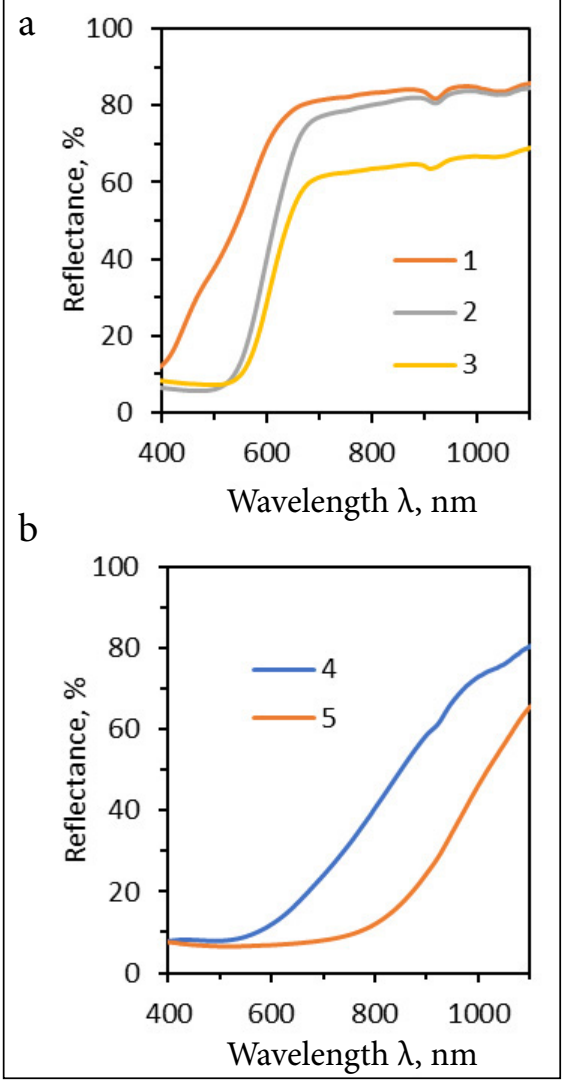

Fig. 5. TI-Se layers reflectance spectra. Concentration of $\mathrm{Tl}^{+}$precursor solution, $\mathrm{mol} / \mathrm{l}$ : (1) 0.025 , $(2,4,5) 0.1,(3) 0.8$. Duration of treatment in $\mathrm{Tl}^{+}$ precursor solution, min: $(1,2,3,5) 75$, (4) 20. Coloured online
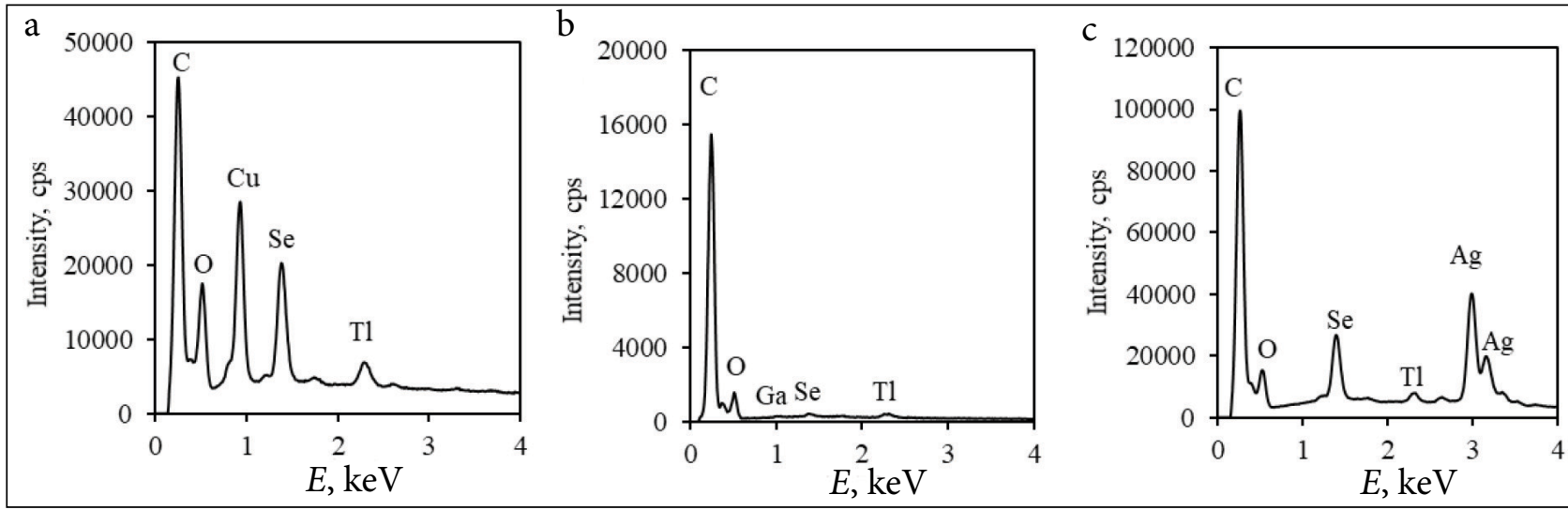

Fig. 4. Representative EDS patterns of the surfaces of TI-M-Se layers: (a) TI-Cu-Se, (b) Tl-Ga-Se, (c) Tl-Ag-Se. The data of corresponding elemental analysis assessed by EDS are shown in Table 4 
and the reflection of the Tl-Se layers is higher in the longer wavelength part. Meanwhile, the reflectance of these layers does not exceed $20 \%$ at a radiation wavelength of $<434 \mathrm{~nm}(0.025 \mathrm{~mol} / \mathrm{l})$, $<567 \mathrm{~nm}(0.1 \mathrm{~mol} / \mathrm{l})$ and $<583 \mathrm{~nm}(0.8 \mathrm{~mol} / \mathrm{l})$. While, the reflectance at wavelength of $1100 \mathrm{~nm}$ reaches $86 \%(0.025 \mathrm{~mol} / \mathrm{l}), 85 \%(0.1 \mathrm{~mol} / \mathrm{l})$ and $69 \%(0.8 \mathrm{~mol} / \mathrm{l})$. With an increase in the duration of treatment with the $\mathrm{Tl}^{+}$precursor solution from 20 to $75 \mathrm{~min}$, the reflection of electromagnetic radiation decreases in the entire wavelength range under consideration and the reflection of the Tl-Se layers increases in the longer wavelength range. As can be seen from Fig. 5 b, the reflectance of these layers does not exceed $20 \%$ at a radiation wavelength of $<669 \mathrm{~nm}(20 \mathrm{~min})$ and $<871 \mathrm{~nm}(75 \mathrm{~min})$. While, the reflectance at wavelength of $1100 \mathrm{~nm}$ is $81 \%$ (20 $\mathrm{min})$ and $66 \%$ (75 $\mathrm{min})$.

Thus, a redshift of reflection was observed in both cases, both with an increase in the concentration of the $\mathrm{Tl}^{+}$precursor solution and with increasing the duration of treatment of the selenised polymer with this solution.

The Kubelka-Munk [43] theory was used to analyse spectra. The following formula links reflection with absorption coefficient:

$$
F(R)=\frac{\alpha}{S}=\frac{(1-R)^{2}}{2 R} .
$$

Here $F(R)$ is the Kubelk-Munk function, $R$ is the reflectance, $\alpha$ is the absorption coefficient and $s$ is the scattering factor.
$F(R)$ is proportional to the absorption coefficient $\alpha$, because the scattering factor is not dependent on the wavelength. By extrapolating the linear part's intersection with abscissa in the $F(R)=f(\lambda)$ graph we found the absorption edge (Fig. 6).

The graph of the Kubelka-Munk function shows (Fig. 6a) that after the treatment of selenised PA sheet samples with a $\mathrm{Tl}^{+}$precursor with the addition of $\mathrm{KOH}$, the absorption edge values are observed in the visible part of the spectrum. With an increase in the concentration of the $\mathrm{Tl}^{+}$precursor solution from 0.025 to $0.8 \mathrm{~mol} / \mathrm{l}$, a redshift of the absorption edge from 471 to $600 \mathrm{~nm}$ was observed (Fig. 6a). When the selenised polymer samples were treated with the $\mathrm{Tl}^{+}$precursor solution with added ammonia, absorption edge values were observed in the red and infrared regions of the spectrum. With an increase in the duration of treatment with the $\mathrm{Tl}^{+}$precursor solution from 20 to $75 \mathrm{~min}$, a redshift of the absorption edge from 721 to $931 \mathrm{~nm}$ was also observed (Fig. 6b).

To find the exact bandgap value we need to find out the type of transition. The Tauc plot was used to determine band gap values of the studied layers [44]:

$$
\alpha h v=B\left(h v-E_{g}\right)^{1 / m} .
$$

Here $B$ is the constant associated with absorption and not dependable on energy, $E_{\mathrm{g}}$ is the band gap, $\mathrm{eV}$ and $m$ is the power factor of the transition mode.

Depending on a transitional type, the exponential factor $m$ may have these values: $m=2$ direct
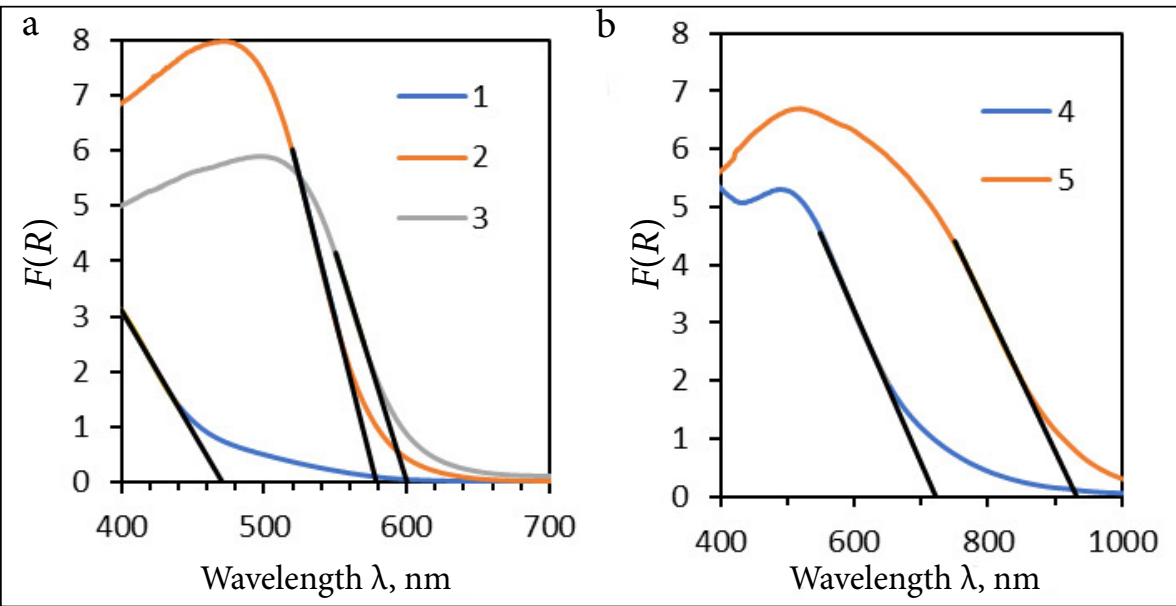

Fig. 6. Tl-Se layers Kubelka-Munk transformation plot of the $\mathrm{Tl}^{+}$precursor solution concentration, $\mathrm{mol} / \mathrm{l}$ : (1) $0.025,(2,4,5) 0.1,(3) 0.8$. Duration of treatment in the $\mathrm{Tl}^{+}$precursor solution, $\min :(1,2,3,5)$ 75 , (4) 20. Coloured online 
allowed transition, $m=2 / 3$ direct forbidden transition, $m=1 / 2$ indirect allowed transition and $m=1 / 3$ indirect forbidden transition. This factor depends on the materials phase state (crystal or amorphous) and photon transition [45. The exponential factor can be determined from the graph $(F(R) h v)^{m}=f(h v)$, because $F(R)$ is proportional to $\alpha$. The intersection of extrapolated linear and abscissa shows the bandgap value (Fig. 7). The transition factor value $m$ is selected such that $E_{g}$ value is closest to the edge of absorption.

As can be seen from Fig. 7a, the bandgap narrows from 2.45 to $1.98 \mathrm{eV}$ when the concentration of the $\mathrm{Tl}^{+}$precursor solution increases from 0.025 to $0.8 \mathrm{~mol} / \mathrm{l}$. With an increase in the duration of treatment with the $\mathrm{Tl}^{+}$precursor solution from 20 to $75 \mathrm{~min}$, the bandgap also narrows from 1.54 to $1.22 \mathrm{eV}$ (Fig. 7b). Thus, on the Tauc plot, a systematic decrease in the bandgap was observed both with an increase in the concentration of $\mathrm{Tl}^{+}$precursor solution and with an increase in the duration of treatment with this solution. The light absorption of the studied layers can be attributed to direct forbidden transitions. The values of the TlSe bandgap found in the literature are in the range from 0.73 to $0.84 \mathrm{eV}$ [46]. The optical parameters of thallium selenides of different stoichiometric compositions were not found. This difference between the bandgaps found in this work and those found in the literature could be due to several reasons. First, the samples treated with the $\mathrm{Tl}^{+}$precursor solution with the addition of $\mathrm{KOH}$ have a low Tl/Se molar ratio. Since the values of the bandgap of elemen- tal selenium vary in the range 1.56-2.4 eV [46], a relatively large bandgap of the Tl-Se layers can be determined by elemental selenium in these layers. Elemental selenium is formed in Tl-Se layers as a result of the reaction of diselenotetrathionate ion with $\mathrm{Tl}^{+}$ions in the polymer (see Eqs. (2) and (6)) or as the final decomposition product of selenopolithionate ions [30]. Second, the reserve TlSe bandgap reported in the literature, determined from the absorption spectra of crystalline samples (indirect transition), was smaller than that found in this work, since direct transitions are characterised by higher bandgaps.

Along the absorption coefficient curve and near the optical band edge there is an exponential part called Urbach tail. It is typical of low crystallinity, unorderly or amorphous materials [47]. The empirical Urbach rule describes the absorption coefficient in low photon energy spectra [48]:

$$
\ln \alpha=\ln \alpha_{0}+\frac{h v}{E_{U}} .
$$

Here $\alpha_{0}$ is the constant and $E_{U}$ is the Urbach energy, eV.

Urbach energy can be calculated from the tangent value of the inclination angle of graph $\ln (F(R))=f(h v)$ linear part, which is equal to $1 / E_{U}$ (Fig. 8). The Urbach energy shows the density of states at the edge of the band and the local microstructural disorder [49].

As can be seen from Fig. 8 a, the calculated Urbach energy values decrease from 0.15 to $0.09-0.10 \mathrm{eV}$

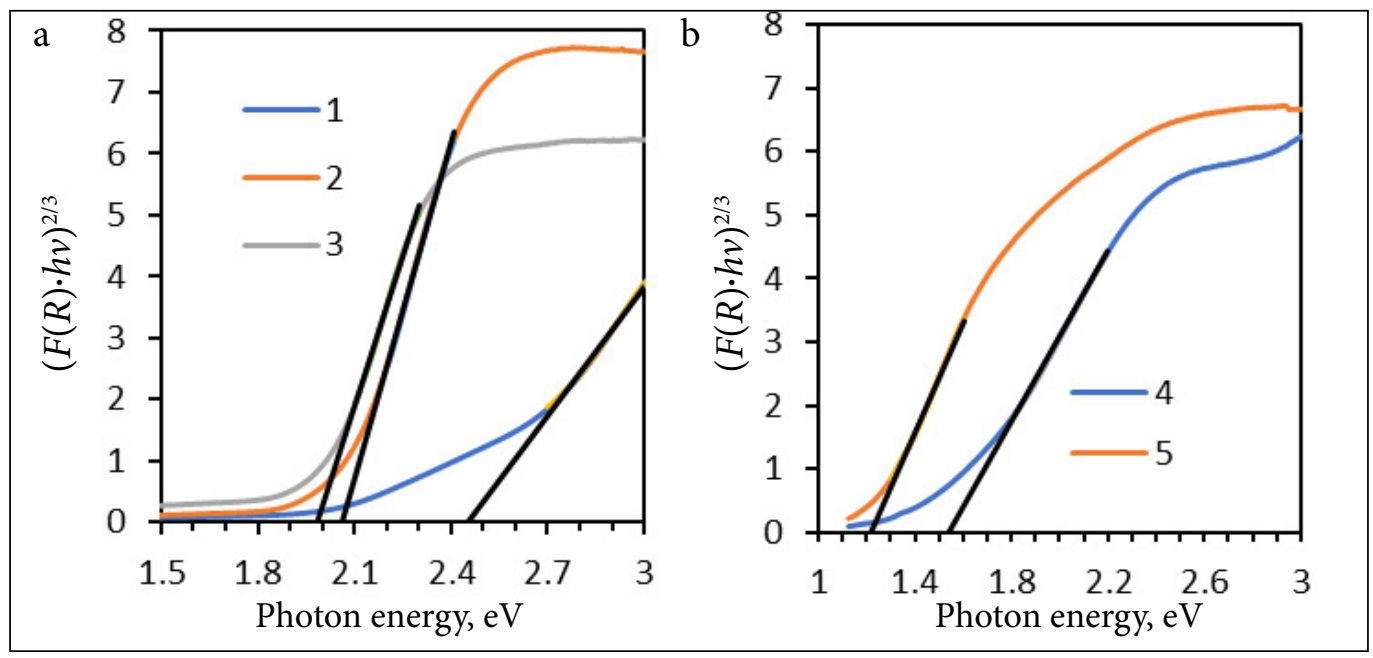

Fig. 7. Tl-Se layers Tauc plot for direct forbidden transitions. Concentration of $\mathrm{Tl}^{+}$precursor solution, $\mathrm{mol} / \mathrm{l}$ : (1) 0.025 , $(2,4,5) 0.1$, (3) 0.8 . Duration of treatment in the $\mathrm{TI}^{+}$salt solution: $(1,2,3,5) 75 \mathrm{~min}$, (4) $20 \mathrm{~min}$. Coloured online 

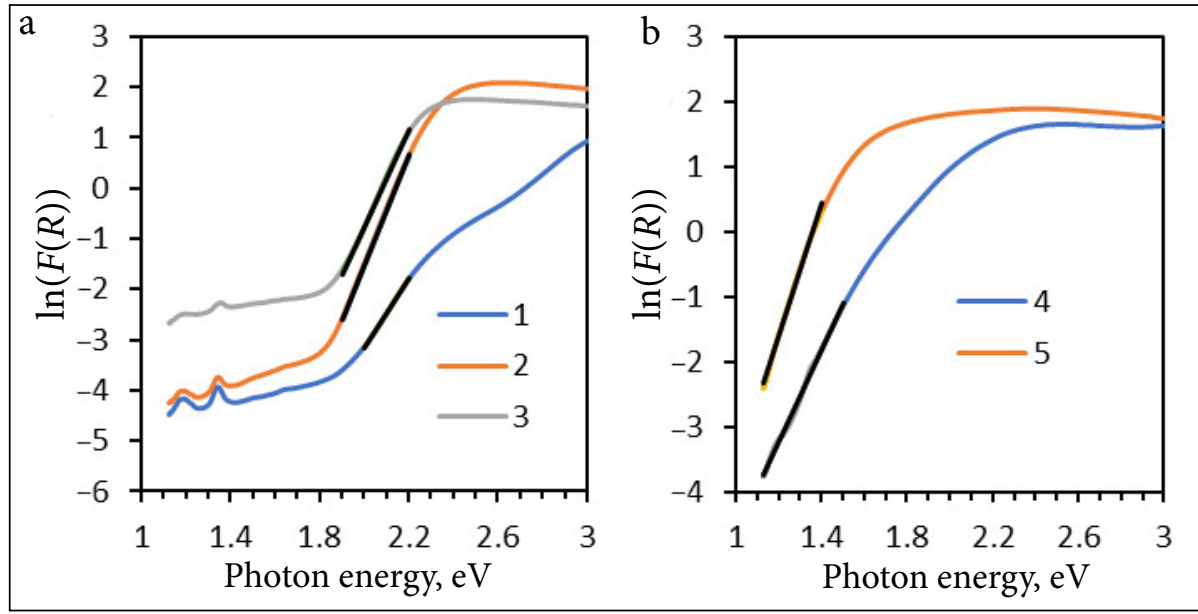

Fig. 8. Plot of the Urbach energy of TI-Se layers. Concentration of $\mathrm{Tl}^{+}$precursor solution, $\mathrm{mol} / \mathrm{l}$ : (1) 0.025 , $(2,4,5) 0.1,(3) 0.8$. Duration of treatment in the $\mathrm{TI}^{+}$salt solution: $(1,2,3,5) 75 \mathrm{~min},(4) 20 \mathrm{~min}$. Coloured online

when the concentration of the $\mathrm{Tl}^{+}$precursor solution increases from 0.025 to $0.8 \mathrm{~mol} / \mathrm{l}$. With an increase in the duration of treatment with the $\mathrm{Tl}^{+}$precursor solution from 20 to $75 \mathrm{~min}$, Urbach energy values also decrease from 0.14 to $0.10 \mathrm{eV}$ (Fig. 8b). It was previously noted [50] that thicker $\mathrm{GeSe}_{2}$ layers are characterised by less structural disorder since structural defects and measured values of Urbach energies decrease with increasing layers thickness.

The steepness parameter $\sigma$ is opposite to the Urbach energy and it represents the broadening of the optical absorption end because of the electron-phonon or exciton-phonon interactions [51]. The following formula is

$$
\sigma=\frac{K^{B} T}{E_{U}},
$$

where $\sigma$ is the steepness parameter, $K^{B}$ is the Boltzman constant $8.617 \cdot 10^{-5}\left(\mathrm{eV} \cdot \mathrm{K}^{-1}\right)$ and $T$ is the absolute temperature $(\mathrm{K})$.
The steepness parameter and electron-phonon interaction $\left(E_{e-p}\right)$ are related [45]:

$$
E_{e-p}=\frac{2}{3 \sigma} \text {. }
$$

The values of the optical parameters of Tl-Se selenide layers are tabulated in Table 5.

Comparing the effect of additives in $\mathrm{Tl}^{+}$precursor solutions on the optical properties of Tl-Se layers, it can be seen that the addition of ammonia leads to a narrower bandgap, but does not significantly affect the local disorder of the microstructure and structural bond defects of the layers. This difference can be explained by the higher concentration of $\mathrm{Tl}^{+}$ions and the higher molar ratio of $\mathrm{Tl} / \mathrm{Se}$ in the layers formed with the addition of ammonia.

In the end, studies of the optical properties of Tl-M-Se mixed layers were carried out. For doping, we used the Tl-Se layers formed by treating selenised PA sheets with the thallium sulfate solution for $20 \mathrm{~min}$. The reflection spectra of

\begin{tabular}{|c|c|c|c|c|c|c|}
\hline $\begin{array}{l}\text { Concentration of } \mathrm{Tl}^{+} \\
\text {soliution, } \mathrm{mol} / \mathrm{l}\end{array}$ & $\begin{array}{l}\text { Duration, } \\
\text { min }\end{array}$ & $\begin{array}{l}\text { Absorption } \\
\text { edge, nm }\end{array}$ & $\underset{\mathrm{nm}, \mathrm{nm}}{\operatorname{Band}}$ & $\begin{array}{l}\text { Urbach energy } \\
\qquad E_{u^{\prime}} \mathrm{eV}\end{array}$ & $\begin{array}{l}\text { Steepness } \\
\text { parameter } \sigma\end{array}$ & $\begin{array}{l}\text { Electron-phonon } \\
\text { interaction } E_{e-p}\end{array}$ \\
\hline 0.025 & \multirow{3}{*}{75} & 471 & 2.45 & 0.15 & 0.17 & 3.83 \\
\hline 0.1 & & 578 & 2.06 & 0.09 & 0.27 & 2.43 \\
\hline 0.8 & & 600 & 1.98 & 0.10 & 0.24 & 2.76 \\
\hline \multirow{2}{*}{0.1} & 20 & 721 & 1.54 & 0.14 & 0.18 & 3.73 \\
\hline & 75 & 931 & 1.22 & 0.10 & 0.26 & 2.60 \\
\hline
\end{tabular}

Table 5. The optical parameters of TI-Se layers 


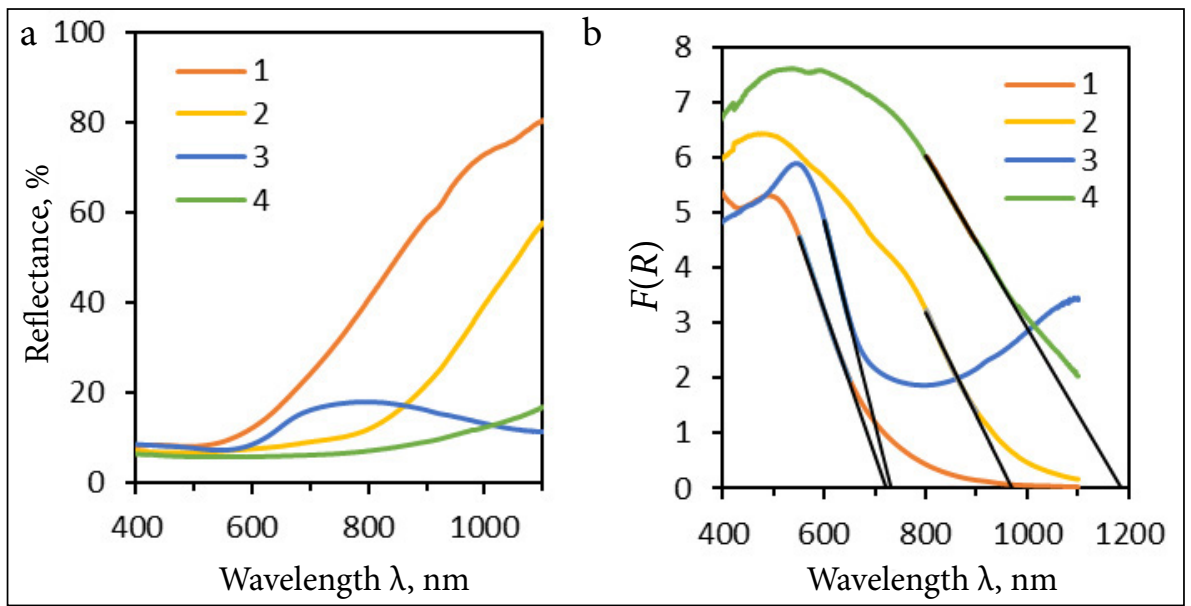

Fig. 9. Reflectance spectra (a) and Kubelka-Munk transformation plot (b) of TI-Se and TI-M-Se layers. (1) TI-Se, (2) TI-Ga-Se, (3) TI-Cu-Se, (4) TI-Ag-Se. Coloured online

these layers in the range $400-1100 \mathrm{~nm}$, as well as the Kubelka-Munk transformation plot, are shown in Fig. 9. Meanwhile, the graphical definition of the reserved bandgap and the Urbach energy of these layers are shown in Fig. 10.

A red shift in the absorption edge (Fig. 9b) and reduction of the bandgap energy (Fig. 10a) were observed after treatment in $\mathrm{Ga}^{3+}, \mathrm{Cu}^{2+} / \mathrm{Cu}^{+}$or $\mathrm{Ag}^{+}$ salt solutions. The optical absorption of investigated layers may be classified under direct forbidden transitions. The light absorption of these layers can be attributed to direct forbidden transitions $(m=2 / 3)$. The values of bandgap of the considered compounds, determined in the study [46], are presented in Table 6 and the optical parameters of the Tl-Se and Tl-M-Se layers, determined in our work, are presented in Table 7 .
As it can be seen from the data presented in Tables 6 and 7 , the bandgap of the Tl-Ga-Se layers is in the range between the values of the bandgap $E_{g}$ of thallium selenide and gallium selenide layers. Meanwhile, the $E_{g}$ value of $1.54 \mathrm{eV}$ in the Tl-CuSe layers is close to the experimentally determined bandgap of Tl-Se layers, since $\mathrm{Cu}_{2} \mathrm{Se} E_{g}=1.23 \mathrm{eV}$ may not have had a significant effect on the reserved bandgap in the mixed layer. The value of $E_{g}=0.86 \mathrm{eV}$, determined for the Tl-Ag-Se layer, is in the range between the values of the reserved bandgap of the $\mathrm{Ag}_{2}$ Se layer $(0.13 \mathrm{eV})$ indicated in the study [46] and the Tl-Se layer $(1.54 \mathrm{eV})$ determined in this work. A common problem in applying the Tauc concept to polycrystalline thin films composed of nanometric crystallites is their size distribution and the resulting variation in the bandgap

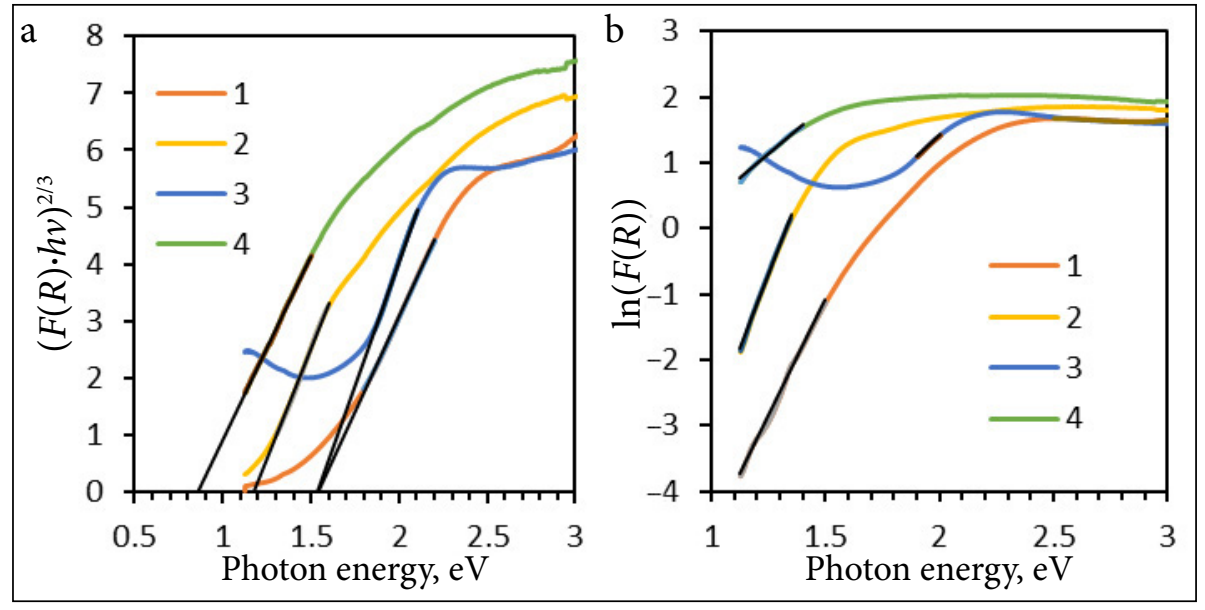

Fig. 10. Tauc plot of TI-Se and TI-M-Se layers for direct forbidden transitions (a) and Urbach energy plot (b). (1) TI-Se, (2) TI-Ga-Se, (3) Tl-Cu-Se, (4) TI-Ag-Se. Coloured online 
Table 6. The $E_{g}$ values of semiconductors [46]

\begin{tabular}{c|cc}
\hline Compound & Band gap Eg, $\mathbf{n m}, \mathbf{e V}$ & Type of transition \\
\hline Se, trigonal & 1.71 & Direct \\
\hline $\mathrm{Se}$, hexagonal & 1.75 & Indirect \\
\hline $\mathrm{TISe}$ & 0.73 & Indirect \\
\hline \multirow{2}{*}{$\mathrm{GaSe}$} & 1.98 & Indirect \\
\hline $\mathrm{Ga}_{2} \mathrm{Se}_{3}$ & 2.12 & Direct \\
\hline $\mathrm{Cu}_{2} \mathrm{Se}$ & 2.05 & - \\
\hline $\mathrm{Ag}_{2} \mathrm{Se}$ & 1.23 & - \\
\hline
\end{tabular}

Table 7. Optical parameters of TI-Se and TI-M-Se layers

\begin{tabular}{c|c|c|c|c|c}
\hline Compound & $\begin{array}{c}\text { Absorption edge, } \\
\mathbf{n m}\end{array}$ & $\begin{array}{c}\text { Band gap } \boldsymbol{E}_{\mathbf{g}^{\prime}} \\
\mathbf{n m}\end{array}$ & $\begin{array}{c}\text { Urbach energy } \boldsymbol{E}_{\mathbf{u}^{\prime}} \\
\mathbf{e V}\end{array}$ & $\begin{array}{c}\text { Steepness parameter } \\
\mathbf{\sigma}\end{array}$ & $\begin{array}{c}\text { Electron-phonon } \\
\text { interaction } \boldsymbol{E}_{\boldsymbol{e}-\boldsymbol{p}}\end{array}$ \\
\hline TI-Se & 721 & 1.54 & 0.14 & 0.179 & 3.730 \\
\hline TI-Ga-Se & 969 & 1.18 & 0.11 & 0.230 & 2.899 \\
\hline Tl-Cu-Se & 734 & 1.54 & 0.30 & 0.084 & 7.972 \\
\hline Tl-Ag-Se & 1183 & 0.86 & 0.34 & 0.075 & 8.857 \\
\hline
\end{tabular}

of the reserve due to quantum localization effects [52]. The discrepancy between the values of the bandgap determined in this work and those published in other studies can be caused by many physical reasons - the size of crystallites, the concentration of charge carriers, impurities, deformation of the crystal lattice and deviations from stoichiometry [53]. Therefore, the relatively lowest Urbach energy of the Tl-Ga-Se layer (Fig. 10b) indicates less disorder of its local microstructure and fewer defects in structural bonds.

\section{CONCLUSIONS}

Thallium selenide layers on polyamide sheets were formed by the two-stage adsorption/diffusion route. The increase in the concentration of $\mathrm{Tl}^{+}$precursor solutions and the duration of the second stage had a positive effect on an increase in the thallium concentration and the Tl/Se molar ratio in the Tl-Se layers. However, the form of the $\mathrm{Tl}^{+}$cations in the precursor solution had the greatest effect on the layer composition. When the thallium ammonia complex was used as a $\mathrm{Tl}^{+}$precursor solution, the thallium concentration, as well as the $\mathrm{Tl} / \mathrm{Se}$ molar ratio in the layer, increase by more than 8 times. After doping the Tl-Se layers with solutions containing $\mathrm{Cu}^{2+} / \mathrm{Cu}^{+}, \mathrm{Ga}^{3+}$ and $\mathrm{Ag}^{+}$cations, mixed
Tl-M-Se $(\mathrm{M}=\mathrm{Cu}, \mathrm{Ga}, \mathrm{Ag})$ layers were successfully formed. The peaks of $\mathrm{Tl}, \mathrm{Se}, \mathrm{Cu}, \mathrm{Ga}$ and Ag originating from these layers confirmed the formation of well-defined thin Tl-Se and Tl-M-Se coating layers on the polyamide substrate sheet.

The studies of optical parameters have shown that with increasing concentration of the $\mathrm{Tl}^{+}$precursor solution and increasing treatment duration, a redshift of reflection and the absorption edge of the formed thallium selenide layers was observed. The samples with higher $\mathrm{Tl}^{+}$cations concentration and $\mathrm{Tl} / \mathrm{Se}$ molar ratio are characterised by a lower bandgap energy, but the synthesis conditions and layer composition do not significantly affect Urbach energy values. Also a redshift in the absorption edge and reduction of the bandgap energy were observed after the treatment in $\mathrm{Ga}(\mathrm{III}), \mathrm{Cu}(\mathrm{II} / \mathrm{I})$ or $\mathrm{Ag}(\mathrm{I})$ salt solutions.

Received 13 April 2021 Accepted 26 April 2021

\section{References}

1. M. Kar, S. Sarkar, P. Sarkar, J. Phys. Chem. C, 124, 11350 (2020).

2. J. D. Peng, Y. T. Wu, M. H. Yeh, F. Y. Kuo, R. Vittal, K. C. Ho, ACS Appl. Mater. Interf., 12, 44597 (2020).

3. L. Huang, J. Lu, D. Ma, et al., J. Mater. Chem. A, 8, 1394 (2020). 
4. Y. Chen, J. Chen, B. Zhang, et al., J. Mater. Sci. Technol., 78, 121 (2021).

5. R. S. Pedanekar, S. K. Shaikh, K. Y. Rajpure, Curr. Appl. Phys., 20, 931 (2020).

6. B. Barman, K. V. Bangera, G. K. Shivakumar, Superlattice. Microst., 137, 106349 (2020).

7. K. C. Kwon, T. H. Lee, S. Choi, et al., Appl. Surf. Sci., 541, 148529 (2021).

8. N. B. Singh, D. R. Suhre, V. Balakrishna, et al., Prog. Cryst. Growth Ch., 37, 47 (1998).

9. A. B. Bhalerao, S. B. Jambure, R. N. Bulakhe, et al., Proceedings of the 7th International Conference on Advances in Energy Research, Singapore (2021).

10. H. M. Pathan, S. S. Kulkarni, R. S. Mane, C. D. Lokhande, Mater. Chem. Phys., 93, 16 (2005).

11. S. Shen, Y. Liang, Y. Ma, B. Huang, W. Wei, Y. Dai, Phys. Chem. Chem. Phys., 20, 14778 (2018).

12. J. Burnett, L. Faoro, T. Lindström, Supercond. Sci. Technol., 29, 044008 (2016).

13. M. G. Kanatzidis, in: Encyclopedia of Inorganic Chemistry, John Wiley \& Sons, Ltd, Chichester, UK (2006).

14. U. Saglam, S. Yakut, B. Karabak, D. Bozoglu, Canadian J. Phys., 97, 1182 (2019).

15. S. Motonami, M. Arita, H. Anzai, et al., J. Phys. Soc. Jpn., 83, 053707 (2014).

16. A. Gaur, K. Khan, A. Soni, et al., Proceedings of the AIP Conference, United States (2020).

17. M. Hashemi, S. M. Bagher Ghorashi, F. Tajabadi, N. Taghavinia, Mat. Sci. Semicon. Proc., 126105676 (2021).

18. F. Khavari, J. Keller, J. K. Larsen, et al., Phys. Status Solidi, 217, 2000415 (2020).

19. S. Levcenko, H. Stange, L. Choubrac, et al., J. Appl. Phys., 127, 125701 (2020).

20. D. Delmonte, R. Manfredi, D. Calestani, et al., Semicond. Sci. Tech., 35, 045026 (2020).

21. A. Biswas, S. Sil, A. Dey, et al., J. Phys. Chem. Solids, 150, 109878 (2021).

22. A. Ivanauskas, R. Ivanauskas, I. Ancutiene, Chalcogenide Lett., 13, 373 (2016).

23. A. Murugan, V. Siva, A. Shameem, S. Asath Bahadur, Int. J. Eng. Adv. Technol., 9, 356 (2019).

24. S. M. Chauhan, S. H. Chaki, M. P. Deshpande, J. P. Tailor, A. J. Khimani, Mat. Sci. Semicon. Proc., 74, 329 (2018).

25. Z. Li, Y. F. Wang, X. W. Wang, Z. Yang, J. H. Zeng, Mater. Lett., 221, 42 (2018).

26. P. Luo, F. Zhuge, Q. Zhang, et al., Nanoscale Horiz., 4, 26 (2019).

27. R. Zeinodin, F. Jamali-Sheini, M. Cheraghizade, Mat. Sci. Semicon. Proc., 123, 105501 (2021).

28. H. Kafashan, Ceram. In., 45, 334 (2019).
29. C.-N. Huang, C.-M. Wu, H.-W. Lo, et al., Polymers, 11, 386 (2019).

30. R. Ivanauskas, Mater. Sci., 15, 243 (2009).

31. R. Ivanauskas, L. Samardokas, M. Mikolajunas, D. Virzonis, J. Baltrusaitis, Appl. Surf. Sci., 317, 818 (2014).

32. R. Ivanauskas, D. Milasiene, J. Phys. Chem. Solids, 145, 109533 (2020).

33. D. Milašiene, R. Ivanauskas, Cent. Eur. J. Chem., 11, 1976 (2013).

34. R. Ivanauskas, J. Baltrusaitis, Appl. Surf. Sci., 283, 360 (2013).

35. R. Ivanauskas, V. Janickis, V. Jasulaitienè, Cent. Eur. J. Chem., 11, 636 (2013).

36. R. Ivanauskas, L. Samardokas, I. Ancutienè, A. Ivanauskas, Mater. Sci., 21, 13 (2015).

37. I. Ancutiene, J. G. Navea, J. Baltrusaitis, Appl. Surf. Sci., 347, 520 (2015).

38. S. J. Gregg, K. S. W. Sing, Adsorption, Surface Area, and Porosity, Academic Press, London (1982).

39. B. Rathke, J. Prakt. Chem. Chem. Ztg., 95, 1 (1865).

40. J. Ponchai, P. Kaewurai, C. Boonthum, et al., RSC $A d v ., 9,12047$ (2019).

41. EPA. Toxicological Review of Thallium and Compounds (CAS No. 7440-28-0). In Support of Summary Information in the Integrated Risk Information System (IRIS), U. S. Environmental Protection Agency, Washington, DC (2009).

42. N. J. W. Reuvers, H. P. Huinink, H. R. Fischer, O. C. G. Adan, Polymer, 55, 2051 (2014).

43. R. Köferstein, L. Jäger, S. Ebbinghaus, S. G. Ebbinghaus, Ionics Solid State Ion., 249-250, 1 (2013).

44. J. Tauc, A. Menth, J. Non-Cryst. Solids, 8-10, 569 (1972).

45. A. S. Hassanien, A. A. Akl, Superlattices Microst., 89, 153 (2016).

46. W. H. Strehlow, E. L. Cook, J. Phys. Chem. Ref. Data, 2, 163 (1973).

47. A. S. Hassanien, A. A. Akl, J. Alloy. Compd., 648, 280 (2015).

48. F. Urbach, Phys. Rev., 92, 1324 (1953).

49. G. Ambrosone, D. K. Basa, U. Coscia, M. Fathallah, J. Appl. Phys., 104, 123520 (2008).

50. R. T. A. Kumar, P. C. Lekha, B. Sundarakannan, D. P. Padiyan, Philos. Mag. A: Mater. Sci., 92, 1422 (2012).

51. H. Kabir, M. M. Rahman, K. M. Uddin, A. H. Bhuiyan, Appl. Surf. Sci., 423, 983 (2017).

52. V. Estrella, M. T. S. Nair, P. K. Nair, Thin Solid Films, 414, 281 (2002).

53. F. I. Ezema, S. C. Ezugwu, P. U. Asogwa, A. B. C. Ekwealor, J. Ovonic Res., 5, 145 (2009). 
Linas Samardokas, Remigijus Ivanauskas, Skirma

Žalenkienè, Algimantas Ivanauskas

TALIO SELENIDŲ SLUOKSNIŲ, SUDARYTŲ

ADSORBCINIU / DIFUZINIU METODU, CHEMINĖS SUDE்TIES IR LEGIRAVIMO ITTAKA JŲ OPTINĖMS SAVYBE்MS

Santrauka

Darbe naudojant dviejų pakopų adsorbcijos / difuzijos procesą poliamido lakšto bandinių paviršiuje buvo sudaryti Tl-Se sluoksniai. Pirmoje proceso pakopoje (a) polimeras buvo iseleninamas kalio selenotritionato tirpale, po to (b) įseleninti bandiniai apdoroti $\mathrm{Tl}^{+}$pirmtaku tirpalais. Gauti Tl-Se sluoksniai naudojant jonų mainų reakcijas buvo sèkmingai legiruoti $\mathrm{Cu}^{+} / \mathrm{Cu}^{2+}, \mathrm{Ga}^{3+}$ ir $\mathrm{Ag}^{+}$ katijonais. Tl-Se sluoksnių ir po jų legiravimo gautų Tl$\mathrm{M}-\mathrm{Se}(\mathrm{M}=\mathrm{Cu}, \mathrm{Ga}, \mathrm{Ag})$ sluoksnių cheminè sudètis buvo tirta energijos dispersijos (EDS) ir atominès absorbcinès (AAS) spektroskopijų metodais. Nustatyta sluoksnių elementų sudetis ir $\mathrm{Tl}^{+}$pirmtako tirpalo koncentracijos, antrosios pakopos trukmès ir $\mathrm{Tl}^{+}$formos tirpale - itaka talio koncentracijai ir Tl/Se moliniam santykiui Tl-Se sluoksniuose. EDS analizès rezultatai patvirtino Tl-Se ir Tl-M-Se ( $\mathrm{M}=\mathrm{Cu}, \mathrm{Ga}, \mathrm{Ag})$ sluoksnių susidarymą poliamido lakštų paviršiuje. Ivertinta sluoksnių sudarymo sąlygų ịtaka jų optiniams parametrams. Remiantis atspindžio spektrais, nustatytos sugerties krašto, draustinés juostos pločio $\left(E_{g}\right)$, Urbacho energijos $\left(E_{U}\right)$, statumo parametro $(\sigma)$ ir elektrono-fonono sąveikos $\left(E_{e-p}\right)$ vertès. 